\title{
AVALIAÇÃO TEMPORAL DO POTENCIAL EROSIVO DAS CHUVAS DE FLORIANÓPOLIS-SC
}

\author{
BACK, Álvaro José - ajb@unesc.net \\ Empresa de Pesquisa Agropecuária e Extensão Rural de Santa \\ Catarina/EPAGRI
}

\author{
POLETO, Cristiano - cristiano.poleto@ufrgs.br \\ Universidade Federal do Rio Grande do Sul /UFRS
}

\begin{abstract}
RESUMO: A erosão hídrica é um dos maiores problemas ambientais, determinando a redução da produtividade agrícola e compromete a qualidade e quantidade dos recursos hídricos. Este trabalho teve como objetivos determinar o potencial erosivo das chuvas da região de Florianópolis (SC), avaliar a variação mensal da erosividade, determinar as probabilidades de ocorrência de erosividade, e ajustar as equações para a estimativa da erosividade da chuva com base nos dados pluviométricos da região. Foram analisados os pluviogramas diários da estação meteorológica de Florianópolis do período de 1985 a 2012. O potencial erosivo foi estimado pelo índice EI30, que considera a energia cinética dos segmentos de chuva multiplicada pela intensidade máxima da chuva em 30 minutos (I30). Foram ajustadas as equações de regressão entre o índice de erosividade (EI30) e os coeficientes de chuva como variável dependente. No período de analisado registrou-se no pluviógrafo de Florianópolis a precipitação média anual $1.638,2 \mathrm{~mm}$, destes $1.314,2 \mathrm{~mm}(80,2 \%)$ foram consideradas chuvas erosivas. Em janeiro e fevereiro as erosividade foram classificadas como muito altas, e em março e dezembro são classificadas como altas. Os menores valores de erosividade ocorrem nos meses de junho a agosto, classificados como muito baixas. O valor médio anual da erosividade é de $7.522 \mathrm{MJ} \mathrm{mm} \mathrm{ha-1} \mathrm{h}^{-1} \mathrm{ano}^{-1}$, classificado como erosividade alta. As equações de regressão ajustadas foram significativas e podem ser usadas para estimar a erosividade da chuva na região de Florianópolis onde somente existem informações observadas em pluviômetros. A distribuição de Gumbel-Chow mostrou aderência aos dados observados pelo teste Kolmogorov-Smirnov. Os valores estimados com diferentes períodos de retorno podem ser usados incluindo um fator de risco na estimativa das perdas de solos por erosão.
\end{abstract}

Palavras- chaves: precipitação; chuvas intensas; energia cinética.

TEMPORAL EVALUATION OF THE RAINFALL EROSIVE POTENTIAL OF FLORIANÓPOLISSC

ABSTRACT: Water erosion is one of the major environmental problem, determining the reduction in agricultural productivity and compromising the quality and quantity of water resources. This study aimed to determine the erosive potential of rainfall in the region of Florianópolis (SC), assess the erosivity's monthly variation, determine the probability of occurrence of erosivity, and adjust the equations to estimate rainfall erosivity based on data rainfall in the region. Daily pluviograms of Florianópolis weather station from the period of 1985 to 2012 were analyzed. The erosive potential was estimated by the EI30 index, which considers the kinetic energy of rain segments multiplied by the maximum rainfall intensity in 30 minutes (I30). Regression equations were adjusted to estimate the erosivity index (EI30) with the rain coefficients as dependent variable. In the analyzed period were recorded in Florianopolis rain gauge the average annual rainfall of $1,638.2 \mathrm{~mm}, 1,314.2 \mathrm{~mm}$ of these $(80.2 \%)$ were considered erosive rainfall. In January and February the erosivity were classified as very high, and in March and December are classified as high. The smallest erosivity values occur in the months of June to August, classified as very low. The annual average erosivity is 7,522 MJ mm há-1 $\mathrm{h}^{-1} \mathrm{ano}^{-1}$, classified as high erosivity. Adjusted regression equations were significant and can be used to estimate rainfall erosivity in Florianópolis region where there are only information observed in rain gauges. The distribution of 
Gumbel-Chow showed adherence to the data observed by the Kolmogorov-Smirnov test. The estimated values with different return periods can be used including a risk factor in estimating the loss of soil erosion.

Keywords: precipitation; heavy rains; kinetic energy

\section{INTRODUÇÃO}

A erosão é um processo natural do componente de evolução dos ecossistemas e da dinâmica das paisagens. Contudo, quando ocorre de forma acelerada pela ação antrópica, pode afetar significativamente a qualidade do solo e da água. Nas últimas décadas a erosão do solo tem sido agravada pela atividade humana, principalmente pela como agricultura e deflorestação. A erosão hídrica é a principal causa de degradação de solos agrícolas, que tem a capacidade produtiva reduzida em razão da perda da camada de solo mais fértil. O transporte e arraste das partículas minerais e orgânicas, além de carrear fertilizantes e pesticidas aplicados na adubação para os lagos, açudes e rios, podendo gerar problemas de assoreamento dos recursos hídricos (CASSOL et al., 2008). O crescimento da população mundial e as mudanças climáticas são fatores que aumentam a exploração do solo e os problemas de erosão (NAIPAL et al., 2015)

A erosão hídrica é considerada como um problema sério a nível mundial do ponto de vista ambiental, econômico e social (SYVITSKI; KETTNER, 2011; LEE; LI, 2015; WANG et al., 2016; SADEGHI et al., 2017). Além de causar a degradação dos solos agrícolas e redução na produtividade, a erosão também contribui com a contaminação e poluição dos recursos hídricos e assoreamento de rios, lagos e reservatórios. Estima-se que, em média, há perda de 1 a $2 \%$ dos volumes dos reservatórios em função da sedimentação (CARVALHO, 2012).

O assoreamento dos rios causa diversos problemas como aumento das inundações e enchentes, dificuldade para navegação, aumento dos custos de captação e tratamento da água. Nos reservatórios, especialmente naqueles destinados a geração de energia elétrica, existe grande preocupação com a erosão na bacia e consequente transporte de sedimentos, uma vez que o assoreamento implica na diminuição da vida útil dos reservatórios, redução na capacidade de regularização da vazão, aumento dos custos de produção de energia elétrica (MAIA; VILLELA, 2006; MORRIS; FAN, 2010; CARVALHO, 2012).

Dentre os tipos de erosão destaca-se a erosão hídrica superficial, que é provocada pelo impacto da chuva no solo e pelo escoamento superficial. A erosão hídrica superficial está associada diretamente com a intensidade da chuva e com as características do solo, como capacidade de infiltração, declividade da superfície, cobertura do solo, tipo de solo, entre outras.

Considerando os efeitos da chuva sobre o solo, a característica de maior influência no fenômeno erosivo é a intensidade, seguida da duração, que é o seu complemento e determina a chuva total. De acordo com Pruski (2009), no processo de ocorrência de erosão hídrica, mais importante que os totais anuais precipitados, sobressaem-se a distribuição do tamanho, a velocidade e a energia cinética das gotas e a intensidade, duração e frequência da chuva, sendo o conjunto destes fatores conhecido como a erosividade da chuva. 
A erosão hídrica é um dos fatores que mais tem contribuído para a redução na produtividade agrícola, sendo acelerada pelo uso de práticas inadequadas de cultivo, que acarretam a exposição do solo aos agentes erosivos. Em um contexto mundial, vem sendo desenvolvidos muitos trabalhos para a avaliação e quantificação das perdas de solo por erosão, e desta forma, determinar as melhores práticas de manejo do solo. Diversos modelos matemáticos vêm sendo elaborados e aperfeiçoados com a finalidade de prever a magnitude das perdas de solo por erosão, visando minimizar as perdas de solo com o propósito de auxiliar no planejamento agrícola (AMORIM et al., 2010).

Dentre estes modelos, ressalta-se a Equação Universal de Perda de Solos (EUPS) (Universal Soil Loss Equation - USLE), que é um dos mais utilizados no mundo, podendo ser utilizado em escala universal, caso que depende de dados locais específicos (BERTONI; LOMBARDI NETO, 1990, KINNEL, 2010). Dentre os fatores inclusos no modelo USLE está o fator erosividade da chuva (R), que é um índice numérico que expressa a capacidade da chuva de causar erosão. O fator erosividade é a variável definida com uma função da energia cinética e a intensidade máxima da chuva em 30 minutos (WISCHMEIER; SMITH, 1958; WISCHMEIER; SMITH, 1978).

Segundo Peñalva-Bazzano et al. (2007) a determinação do valor médio da erosividade, realizada com cálculos computacionais a partir de registros pluviográficos diários de vários anos, permite estudar o impacto ambiental de determinadas práticas agrícolas, desenvolver pesquisas em erosão e planejar ações de conservação do solo, além de obras de engenharia civil, como pontes e represas, entre outras.

Para a determinação da erosividade de uma chuva individual é necessário analisar o respectivo pluviograma desta chuva. Esta metodologia requer a existência de longas séries de dados pluviográficos. Esta exigência está justificada na necessidade de calcular a energia cinética de cada semento de chuva com intensidade constante e na estimativa da chuva com intensidade máxima em 30 minutos, o que exige resolução temporal de 5 minutos ou menos.

Hernando e Romana (2016) apontam a necessidade de séries com mais de 20 anos de registros pluviográficos para a estimativa do fator erosividade. Wischmeier e Smith (1978) ao descrevem a metodologia para o cálculo do índice de erosividade afirmaram que o fator $\mathrm{R}$ deveria ser obtido da análise de um período mínimo de 22 anos, de forma a incluir períodos relativamente secos e outros períodos mais chuvosos.

Vários autores comentam da dificuldade de obter esses dados, tanto no Brasil como em outros países de todas as regiões do globo (MELLO et al., 2007, BESKOW et al., 2009 LEE; LI, 2015; LOBO; BONILLA, 2015). Yin et al. (2015) comentam que mesmo nas redes de estações automáticas de países desenvolvidos, a resolução temporal dos dados não permite o cálculo de forma direta da energia cinética da chuva. Alguns estudos foram realizados com objetivo de estimar a erosividade da chuva para dados de diferente resolução temporal (ZHAN. FU, 2003; SADEGHI et al., 2011; SADEGHI; TAVANGAR, 2015; OLIVEIRA et al., 2012; PANAGOS et al., 2015; BORRELI et al., 2016). 
Para suplementar essa dificuldade na estimativa direta da erosividade várias equações foram propostas para estimar a erosividade média mensal indiretamente a partir de observações diárias de chuva realizadas em pluviômetros. O método mais utilizado é conhecido como índice modificado de Fournier (1956), baseado nas médias mensais e anual de precipitação. Estes dados são disponíveis em muitas estações e com séries mais longas que os registros em pluviógrafos, sendo esta metodologia frequentemente usada na estimativa da erosividade anual e na geração de mapas de erosividade. Para a aplicação deste método indireto é necessário conhecer a equação de regressão que relaciona os dois métodos.

Mello et al. (2013), utilizando-se das equações de 54 estações pluviográficas do Brasil, determinaram o coeficiente de chuva com base nas médias mensais de 773 estações pluviométricas do Brasil, e empregado a análise multivariada geraram mapas de erosividade para o Brasil, demonstrando a eficácia na aplicação dos dados pluviométricos na obtenção das estimativas de erosividade tendo como base as equações definidas a partir de dados pluviográficos.

Este trabalho teve como objetivos analisar as chuvas erosivas do município de Florianópolis (SC), avaliar a variação mensal da erosividade, determinar as probabilidades de ocorrência da erosividade e também ajustar as equações para a estimativa da erosividade da chuva com base nos dados pluviométricos da região.

\section{MATERIAL E MÉTODOS \\ LOCALIZAÇÃO E CARACTERIZAÇÃO DA ÁREA DE ESTUDO}

Foram utilizados os pluviogramas diários do período de 1985 a 2012 da Estação Meteorológica de Florianópolis, localizada na latitude $27^{\circ} 35^{\prime} \mathrm{S}$, longitude $48^{\circ} 34^{\prime} \mathrm{W}$, altitude $2 \mathrm{~m}$ (Figura 1 ). Como esta estação é a única da região do Litoral Centro de Santa Catarina que apresenta dados pluviográficos, a equação ajustada para Florianópolis pode ser usada na estimativa da erosividade dos municípios localizados nesta região.

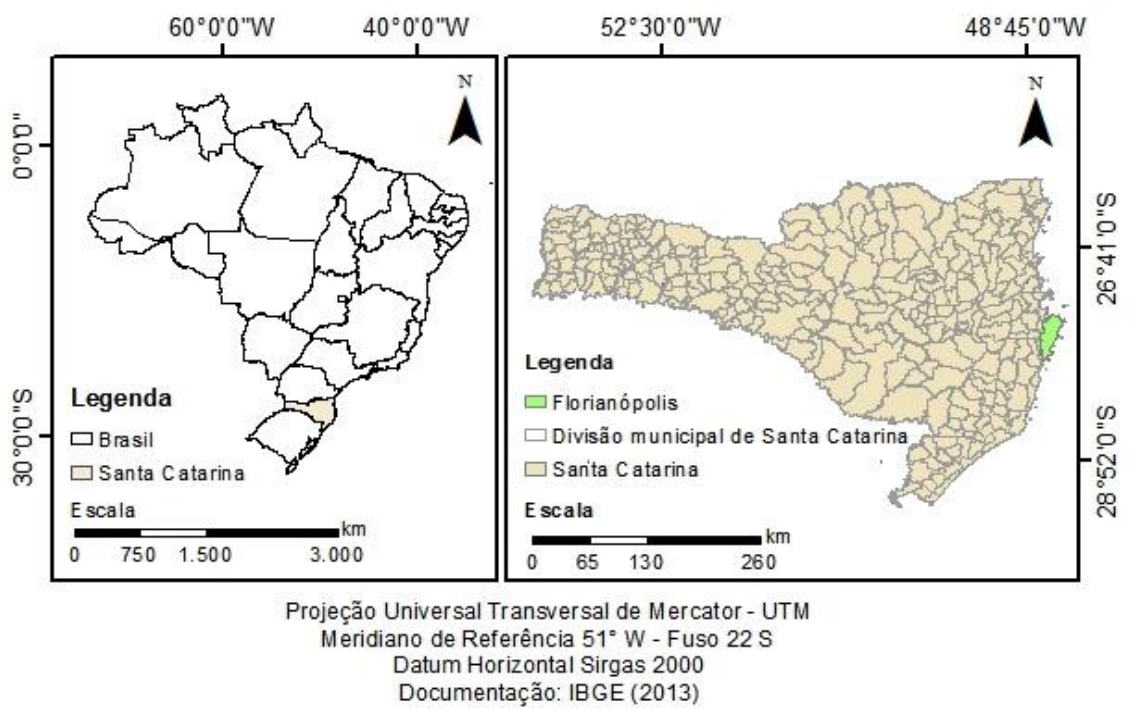

Figura 1 - Localização da área de estudo 
O clima da região é classificado como subtropical constantemente úmido, sem estação seca e com verão quente (Cfa) (ALVARES et al., 2013). De acordo com Thomé et al. (1999), a região de Florianópolis caracteriza-se pela precipitação anual variando de 1.270 a $1.600 \mathrm{~mm}$, com número de dias de chuva no ano variando de 140 a 158 dias. A evapotranspiração anual varia de 943,4 a $983,2 \mathrm{~mm}$. A temperatura mínima mês mais frio é varia de 15 a $16^{\circ} \mathrm{C}$, a temperatura média anual varia de 19,0 a $19,5^{\circ} \mathrm{C}$, e a temperatura máxima varia de 26,1 a $26,5^{\circ} \mathrm{C}$.

\section{CÁLCULO DA EROSIVIDADE}

Os pluviogramas foram digitalizados e com um programa de computador elaborado por Valvassori e Back (2014) foram realizados os cálculos para a classificação das chuvas e obtenção do índice de erosividade. No programa constam os seguintes procedimentos:

1) A identificação da chuva individual, adotando os critérios sugeridos por Wischmeier e Smith (1958), descritos em Cabeda (1976), em que foi considerada chuva individual aquela separada da anterior e da posterior por um período mínimo de $6 \mathrm{~h}$ sem chuva ou com menos de $1 \mathrm{~mm}$;

2) A identificação da chuva erosiva como sendo aquelas com quantidade igual ou superior a $10 \mathrm{~mm}$ ou igual ou superior a $6 \mathrm{~mm}$ em um período máximo de 15 min;

3) O cálculo da energia cinética unitária de cada segmento uniforme de chuva foi obtida pela expressão proposta por Wischmeier e Smith (1978) em unidades do sistema internacional:

$$
\mathrm{EC}=0,119+0,0873 \log (\mathrm{i})
$$

Sendo: EC a energia cinética unitária ( $\left.\mathrm{MJ} \mathrm{ha}^{-1} \mathrm{~mm}^{-1}\right)$; i é a intensidade da chuva dada em $\mathrm{mm} \mathrm{h}^{-1}$ no segmento considerado.

De acordo com Foster et al. (1981), como o diâmetro das gotas de chuva não aumenta quando as intensidades são iguais ou superiores a $76 \mathrm{~mm}$ $\mathrm{h}^{-1}$, a energia cinética foi considerada igual a 0,283 $\mathrm{MJ} \mathrm{ha}^{-1} \mathrm{~mm}^{-1}$ para intensidade superiores a $76 \mathrm{~mm}^{-1}$;

4) O cálculo da energia cinética do segmento expressa em $\mathrm{MJ} \mathrm{ha}^{-1}$, a partir da multiplicação da EC pela quantidade de chuva no respectivo segmento uniforme, isto é:

$$
\mathrm{ECs}=\mathrm{ECh}
$$

Em que: Ecs é a energia cinética do segmento ( $M \mathrm{~J} \mathrm{ha}^{-1}$ ); h é a altura pluviométrica do segmento $(\mathrm{mm})$;

5) O cálculo da energia cinética total da chuva, somando-se a energia cinética de cada segmento uniforme, isto é: 
$\mathrm{ECt}=\Sigma \mathrm{ECS}$ (I30);

6) O cálculo da intensidade máxima da chuva em um período de $30 \mathrm{~min}$

7) Determinação do índice EI30 que representa a erosividade de cada chuva individual e erosiva através da seguinte expressão, conforme Cassol et al. (2007):

$$
\mathrm{EI} 30=\mathrm{ECt} \mathrm{I} 30
$$

Em que: EI30 é o índice de erosividade da chuva erosiva individual (MJ $\mathrm{mm} \mathrm{ha}^{-}$ $\left.{ }^{1} \mathrm{~h}^{-1}\right)$; ECt é a energia cinética total da chuva (MJ ha-1); I30 é a intensidade máxima média de precipitação em $30 \mathrm{~min}\left(\mathrm{~mm} \mathrm{~h}^{-1}\right)$;

8) A obtenção das somas mensais e anuais dos índices EI30 determinados para cada chuva individual e erosiva.

Com a média da erosividade anual das chuvas no período analisado tem-se o Fator R da Equação Universal de Perda de Solo para aplicação em Florianópolis e na região do entorno com características climáticas semelhantes.

Para analisar os resultados de erosividade da chuva foi utilizada a classificação adotada por Santos (2008), conforme indica a tabela 1.

Tabela 1 - Classes de erosividade da chuva média anual e mensal

\begin{tabular}{ccc}
\hline Classe de & \multicolumn{2}{c}{ Valores de erosividade } \\
\cline { 2 - 3 } erosividade & $\mathrm{MJ} \mathrm{mm} \mathrm{ha}^{-1} \mathrm{~h}^{-1} \mathrm{ano}^{-1}$ & $\mathrm{MJ} \mathrm{mm} \mathrm{ha} \mathrm{h}^{-1} \mathrm{mês}^{-1}$ \\
\hline Muito baixa & $\mathrm{R}<2.500$ & $\mathrm{R}<250$ \\
Baixa & $2.500<\mathrm{R}<5.000$ & $250<\mathrm{R}<500$ \\
Média & $5.000<\mathrm{R}<7.000$ & $700<\mathrm{R}<700$ \\
Alta & $7.000<\mathrm{R}<10.000$ & $\mathrm{R}>1.000$ \\
Muito alta & $\mathrm{R}>10.000$ &
\end{tabular}

\section{ESTIMATIVA DE EVENTOS EXTREMOS DE EROSIVIDADE}

Com os valores da intensidade máxima em 30 min (I30) e do índice de erosividade anual de chuva (EI30), foram estimados o período de retorno de 2 , $5,10,20,25,50$ e 100 anos. Para a determinação do período de retorno foi utilizada a distribuição de Gumbel-Chow e a aderência dos dados a distribuição foi avaliada com o teste de Kolmogorov-Smirnov ao nível de significância de $5 \%$, conforme metodologia descrita em Kite (1977). 
Pela distribuição de Gumbel-Chow o evento máximo com determinado período de retorno pode ser estimado como:

$$
X_{T}=\bar{x}+(Y-Y n) \frac{S}{S n}
$$

em que: $\mathrm{X}_{\mathrm{T}}$ é o evento máximo com período de retorno $\mathrm{T}$ anos, $\mathrm{mm} ; \bar{x}$ é a média da série de máximas anuais, $\mathrm{mm}$; $\mathrm{S}$ é o desvio padrão da série de máximas anuais, $\mathrm{mm}$; Yn é a média da variável reduzida; Sn é o desvio padrão da variável reduzida; e $Y$ é a variável reduzida, calculada por:

$$
Y=-\ln \left\{-\ln \left(1-\frac{1}{\mathrm{~T}}\right)\right\}
$$

em que T é o período de retorno (anos).

\section{AJUSTE DA EQUAÇÃO PARA ESTIMATIVA DA EROSIVIDADE PELO MÉTODO PLUVIOMÉTRICO}

Com os valores do índice de erosividade das chuvas e a chuva mensal e anual foram estabelecidas as relações linear e potencial entre a erosividade das chuvas calculada pelo Índice EI30 e o coeficiente de chuvas, conforme proposto por Lombardi Neto (1977) pelas seguintes equações:

$$
\begin{aligned}
& E I 30=a+b R c \\
& E I 30=a R c b
\end{aligned}
$$

em que EI30 é o índice de erosividade das chuvas ( $M J \mathrm{~mm} \mathrm{ha}^{-1} \mathrm{~h}^{-1}$ ); a e b são coeficientes de ajuste; Rc é o coeficiente da chuva, em mm, dado pela seguinte relação:

$$
\mathrm{Rc}=\frac{(\mathrm{Pm})^{2}}{\mathrm{~Pa}}
$$

em que Pm é a precipitação média mensal, em $\mathrm{mm}$; Pa é a precipitação média anual, em $\mathrm{mm}$.

\section{RESULTADOS E DISCUSSÃO}

No período de 1985 a 2012 foram registrados no pluviógrafo de Florianópolis a precipitação média anual de $1.638,2 \mathrm{~mm}$, destes $1.314,2 \mathrm{~mm}$ $(80,2 \%)$ foram consideradas chuvas erosivas e $324,0 \mathrm{~mm}(19,8 \%)$ de chuvas não erosivas (tabela 2). Valvassori e Back (2014) analisando dados de Urussanga, no sul do estado de Santa Catarina, obtiveram valores 
semelhantes, em onde as chuvas erosivas representavam $77,7 \%$ da chuva anual. Back et al. (2016) observaram que para Chapecó, no extremo oeste do estado de Santa Catarina, as chuvas erosivas representaram $87 \%$ da chuva total anual.

Bertol (1993) analisando dados de Lages do período de 1989 a 1990 e Schick et al. (2014), analisando dados de 1989 a 2012, encontraram o valor de $83 \%$ de chuvas erosivas. Bertol et al. (2002) assim como Schick et al. (2014) já alertaram que o elevado percentual do volume de chuvas erosivas em relação ao total indica a necessidade de preocupação com o uso de práticas conservacionistas na região.

No Rio Grande do Sul Peñalva Bazzano et al. (2007) observaram que em Quaraí as chuvas erosivas representam $90 \%$ do volume da precipitação anual. Para Rio Grande (RS), Peñalva Bazzano et al. (2010) observaram que as chuvas erosivas representam $99,3 \%$ da chuva total anual. Martins et al. (2010) analisando erosividade de chuvas do Espirito Santo observaram que as chuvas erosivas representam $88 \%$ do volume da precipitação total. Lombardi Neto 1977 analisando série de 22 anos de dados pluviográficos de Campinas (SP), no sudeste do Brasil, constatou que apenas $74 \%$ do volume das chuvas foram computadas como chuvas erosivas.

Tabela 2 - Chuvas erosivas e chuvas não erosivas e índice de erosividade (EI30) de Florianópolis, SC.

\begin{tabular}{cccccc}
\hline \multirow{2}{*}{ Período } & \multicolumn{2}{c}{ Chuvas não erosivas } & \multicolumn{2}{c}{ Chuvas erosivas } & Chuva total \\
\cline { 2 - 5 } & $(\mathrm{mm})$ & $\%$ & $(\mathrm{~mm})$ & $\%$ & $(\mathrm{~mm})$ \\
\hline Janeiro & 37,3 & 16,5 & 189,0 & 83,5 & 226,2 \\
Fevereiro & 37,7 & 18,5 & 166,0 & 81,5 & 203,7 \\
Março & 39,2 & 23,8 & 125,2 & 76,2 & 164,4 \\
Abril & 23,3 & 21,3 & 86,4 & 78,7 & 109,7 \\
Maio & 20,0 & 17,2 & 96,1 & 82,8 & 116,1 \\
Junho & 16,8 & 26,0 & 47,8 & 74,0 & 64,6 \\
Julho & 19,2 & 22,0 & 68,2 & 78,0 & 87,4 \\
Agosto & 14,8 & 19,2 & 62,2 & 80,8 & 77,0 \\
Setembro & 26,3 & 18,6 & 114,9 & 81,4 & 141,3 \\
Outubro & 28,8 & 19,8 & 116,6 & 80,2 & 145,4 \\
Novembro & 29,3 & 20,1 & 116,5 & 79,9 & 145,8 \\
Dezembro & 31,3 & 20,0 & 125,3 & 80,0 & 156,6 \\
Ano & 324,0 & 19,8 & $1.314,2$ & 80,2 & $1.638,2$ \\
\hline
\end{tabular}

Os valores de erosividade mensal e anual das chuvas são apresentados na tabela 3. Nos valores mensais de erosividade existe uma variação acentuada, onde se observa que em vários meses a erosividade foi nula, significando que as chuvas ocorridas naquele mês não foram classificadas como erosivas. Existem alguns valores de erosividade mensais extremamente altos, como observado em dezembro de 1995 (EI30 $=10.962 \mathrm{MJ} \mathrm{mm} \cdot \mathrm{ha}^{-1} \cdot \mathrm{h}^{-1}$ ) e fevereiro de $1995\left(\right.$ EI30 $\left.=8.555 \mathrm{MJ} \mathrm{mm} \cdot \mathrm{ha}^{-1} \cdot \mathrm{h}^{-1}\right)$. Estes valores se explicam pela ocorrência de valores extremos de chuvas intensas como, por exemplo, 
registrado em fevereiro de 1995, quando foi observado um evento com 437,7 $\mathrm{mm}$ de chuva em 24 horas.

Os maiores valores de erosividade ocorrem no período de dezembro a março, com médias superiores a $900 \mathrm{MJ} \mathrm{mm}^{\mathrm{ha}}{ }^{-1} \mathrm{~h}^{-1} \mathrm{mês}^{-1}$. Em janeiro e fevereiro a erosividade foi classificada como muito alta (acima de $1.000 \mathrm{MJ}$ $\mathrm{mm}$. ha-1 $\mathrm{h}^{-1}$ ), e em março e dezembro foi classificada como alta. Os menores valores de erosividade média ocorrem nos meses de junho a agosto, com erosividade inferior a $250 \mathrm{MJ} \mathrm{mm} \cdot \mathrm{ha}^{-1} \cdot \mathrm{h}^{-1}$, classificadas como muito baixas. A distribuição sazonal da chuva, e consequentemente da erosividade está relacionada com os mecanismos formadores das chuvas na região, onde destacam-se os deslocamentos das frentes frias e ciclones.

Prudêncio (2002) e Franco et al. (2006) descrevem a influência da brisa marítima e terrestre na circulação atmosférica na região do Litoral Norte e do Litoral Centro de Santa Catarina, principalmente nos meses de novembro a fevereiro. Grimm et al. (1989) apresentam a climatologia da precipitação em Santa Catarina, onde mostram que a estação de verão aparece como a mais chuvosa nas áreas litorâneas e do Vale do Itajaí. No verão o aquecimento da superfície e o aporte de umidade para dentro do continente tendem a instabilizar a atmosfera, aumentando os processos convectivos, produzindo chuvas intensas e maiores valores de erosividade.

O valor médio anual da erosividade para Florianópolis é de $7.522 \mathrm{MJ}$ $\mathrm{mm} \cdot \mathrm{ha}^{-1} \cdot \mathrm{h}^{-1}$, classificado como erosividade alta. Estes valores estão coerentes com outros trabalhos de erosividade realizados no Brasil. Lombardi Neto (1977) realizou importante trabalho com registro de chuvas de 22 anos de Campinas (SP), obtendo o índice de erosividade $\mathrm{EI}_{30}$ médio de $6769 \mathrm{MJ} \mathrm{mm}$.ha${ }^{1} \cdot \mathrm{h}^{-1}$.ano ${ }^{-1}$. Estes autores observaram que em Campinas $90,7 \%$ do índice de erosividade estiveram associados ao período de outubro a março, sendo que nesse período a chuva correspondente foi de $80,1 \%$.

Cogo et al. (1978) calcularam o índice de erosividade $\mathrm{EI}_{30}$ para municípios do Rio Grande do Sul obtendo valores médios de 6275, 8606 e $7695 \mathrm{MJ} \mathrm{mm} \cdot \mathrm{ha}^{-1} \cdot \mathrm{h}^{-1}$. ano ${ }^{-1}$. Santos (2008) analisando a série de 45 anos de dados pluviográficos de Pelotas (RS) observou a que a precipitação média anual de $1357,4 \mathrm{~mm}$ e erosividade 5601,9 MJ mm.ha ${ }^{-1} \cdot \mathrm{h}^{-1}$.ano ${ }^{-1}$. Vários estudos realizados com dados pluviográficos do estado do Rio Grande do Sul (CASSOL et al., 2008; PEÑALVA BAZZANO et al., 2007; MAZURANA et al., 2009; PEÑALVA BAZZANO et al., 2010) mostram que a erosividade varia de 5135 a $11297 \mathrm{MJ} \mathrm{mm}$. ha ${ }^{-1} \cdot \mathrm{h}^{-1}$.ano-1, para valores de precipitação média anual variando de 1162 a 1832 mm. Gonçalves et al. (2006) trabalhando com várias estações do Rio de Janeiro encontraram valores médios variando de 4.118 a $16.225 \mathrm{MJ} \mathrm{mm} \cdot \mathrm{ha}^{-1} \cdot \mathrm{h}^{-1} \cdot \mathrm{ano}^{-1}$. Embora alguns estudos realizados no Brasil mostram que a erosividade apresenta correlação significativa com a precipitação média anual e com a longitude (OLIVEIRA et al., 2012; MELLO et al. 2013), estudos com dados locais são necessários devida e grande variação nas séries anuais de erosividade.

Valvassori e Back (2014) analisando série de dados do período de 1980 a 2011 registrados no pluviógrafo de Urussanga, localizada no Sul do estado de Santa Catarina, encontraram valores de $\mathrm{R}$ variando de $2.847 \mathrm{MJ} \mathrm{mm} . \mathrm{ha}^{-1} \cdot \mathrm{h}^{-}$ ${ }^{1}$.ano ${ }^{-1}$ a $12.091 \mathrm{MJ} \mathrm{mm} . \mathrm{ha}^{-1} \cdot \mathrm{h}^{-1}$.ano-1, com média de $5.665 \mathrm{MJ} \mathrm{mm} . \mathrm{ha}^{-1} . \mathrm{h}^{-}$ ${ }^{1}$.ano ${ }^{-1}$. Back et al. (2016) analisando série de 39 anos de pluviógrafo de Chapecó, SC contataram que a erosividade anual variou de 4.838,0 a $15.019,1$ MJ mm.ha-1.h-1.ano-1 com média de $9.045,0 \mathrm{MJ} \mathrm{mm} \mathrm{ha}^{-1} \cdot \mathrm{h}^{-1} \cdot$ ano $^{-1}$. Outros 
trabalhos sobre erosividade para Santa Catarina foram realizados por Bertol (1993) e Bertol (1994), que encontrou erosividade média anual de $5.694 \mathrm{MJ}$ $\mathrm{mm} \mathrm{ha}{ }^{-1} \cdot \mathrm{h}^{-1} \cdot \mathrm{ano}^{-1}$ e $6.329 \mathrm{MJ} \mathrm{mm} \cdot \mathrm{ha}^{-1} \cdot \mathrm{h}^{-1}$. ano-1, respectivamente para Lages e para Campos Novos.

Tabela 3 - Valores mensais de erosividade $\mathrm{EI}_{30}\left(\mathrm{MJ} \cdot \mathrm{mm} \cdot \mathrm{ha}^{-1} \cdot \mathrm{h}^{-1} \cdot \mathrm{mês}^{-1}\right)$ das chuvas registradas em Florianópolis, SC.

\begin{tabular}{|c|c|c|c|c|c|c|c|c|c|c|c|c|c|}
\hline Ano & Jan. & Fev. & Mar. & Abr. & Maio & Jun. & Jul. & Ago. & Set. & Out. & Nov. & Dez & Total \\
\hline 1985 & 1.732 & 2.050 & 995 & 74 & 34 & 0 & 79 & 36 & 164 & 153 & 592 & 0 & 1.732 \\
\hline 1986 & 816 & 1.181 & 571 & 475 & 67 & 17 & 26 & 66 & 459 & 925 & 497 & 437 & 816 \\
\hline 1988 & 176 & 182 & 1.199 & 295 & 53 & 27 & 0 & 0 & 301 & 485 & 52 & 60 & 2.830 \\
\hline 1989 & 1.948 & 1.192 & 293 & 256 & 360 & 40 & 74 & 172 & 934 & 85 & 47 & 387 & 5.789 \\
\hline 1990 & 552 & 2.622 & 621 & 2.090 & 65 & 48 & 621 & 150 & 198 & 495 & 408 & 483 & 8.353 \\
\hline 1991 & 958 & 498 & 243 & 90 & 443 & 109 & 0 & 80 & 90 & 777 & 7.300 & 1.038 & 11.626 \\
\hline 1992 & 1.733 & 687 & 437 & 45 & 268 & 70 & 219 & 139 & 63 & 0 & 395 & 118 & 4.174 \\
\hline 1993 & 847 & 716 & 514 & 254 & 428 & 157 & 438 & 0 & 440 & 317 & 0 & 476 & 4.588 \\
\hline 1994 & 433 & 3.538 & 1.870 & 454 & 787 & 152 & 133 & 11 & 0 & 215 & 494 & 1229 & 9.315 \\
\hline 1995 & 1.077 & 1.091 & 1.487 & 119 & 0 & 177 & 40 & 78 & 91 & 347 & 547 & 10.692 & 15.746 \\
\hline 1996 & 878 & 1.549 & 831 & 42 & 1.927 & 445 & 180 & 223 & 288 & 116 & 70 & 427 & 6.978 \\
\hline 1997 & 4.670 & 1.228 & 58 & 603 & 70 & 60 & 54 & 13 & 1.469 & 1030 & 399 & 912 & 10566 \\
\hline 1998 & 1.303 & 626 & 211 & 1.056 & 81 & 55 & 80 & 377 & 684 & 279 & 559 & 200 & 5.565 \\
\hline 1999 & 1852 & 1.477 & 112 & 147 & 34 & 274 & 225 & 28 & 65 & 733 & 1.319 & 172 & 6.438 \\
\hline 2000 & 2.248 & 487 & 4.470 & 207 & 0 & 140 & 59 & 32 & 363 & 506 & 77 & 995 & 9.584 \\
\hline 2001 & 522 & 8.555 & 1.024 & 1.100 & 2.583 & 220 & 82 & 156 & 79 & 991 & 553 & 170 & 16.034 \\
\hline 2002 & 719 & 161 & 645 & 716 & 408 & 7 & 254 & 179 & 148 & 208 & 171 & 594 & 4.210 \\
\hline 2003 & 866 & 267 & & 55 & 27 & 118 & 17 & 0 & 194 & 274 & 92 & 675 & 2.669 \\
\hline 2004 & 2.667 & 1.308 & 921 & 346 & 650 & 165 & 42 & 40 & 335 & 258 & 224 & 1.454 & 8.409 \\
\hline 2005 & 1.068 & 1.398 & 1.073 & 697 & 535 & 42 & 107 & 179 & 662 & 621 & 124 & 219 & 6.726 \\
\hline 2006 & 939 & 568 & 177 & 524 & 77 & 0 & 16 & 45 & 13 & 54 & 614 & 132 & 3.160 \\
\hline 2007 & & 729 & 1.339 & 19 & 221 & 0 & 393 & 21 & 390 & 381 & 154 & 729 & 4.449 \\
\hline 2008 & 1.535 & 4.694 & 1.096 & 647 & 304 & 12 & 0 & 61 & 690 & 457 & 2.421 & 1.720 & 13.637 \\
\hline 2009 & 681 & 571 & 1.562 & 1.612 & 49 & 13 & 110 & 149 & 973 & 102 & 224 & 498 & 6.543 \\
\hline 2010 & 1394 & 1.342 & 1.299 & 178 & 4.991 & 115 & 113 & 103 & 322 & 341 & 636 & 79 & 10.914 \\
\hline 2011 & 2.050 & 1401 & 1.143 & 28 & 145 & 72 & 209 & 810 & 628 & 129 & 79 & 1.963 & 8.656 \\
\hline 2012 & 1.278 & 92 & 1.040 & 116 & 243 & 517 & 110 & 170 & 0 & 0 & 74 & 86 & 3.726 \\
\hline Média & 1.297 & 1.489 & 938 & 454 & 550 & 113 & 136 & 123 & 372 & 381 & 671 & 963 & 7.522 \\
\hline
\end{tabular}

Na figura 2 estão representados os valores de precipitação total anual e a erosividade total anual, onde se observa que existe uma relação direta entre estas variáveis (coeficiente de correlação $r=0,82$ ), porém a precipitação total não explica completamente a variação da erosividade. Nos anos de 1995 e 2001 foram observados os maiores valores do índice de erosividade anual, 15.746 MJ mm.ha-1.h $\mathrm{h}^{-1}$. ano ${ }^{-1}$ e $16.034 \mathrm{MJ} \mathrm{mm} \cdot \mathrm{ha}^{-1} \cdot \mathrm{h}^{-1}$. ano ${ }^{-1}$, respectivamente. 
No entanto, os maiores totais de precipitação anual foram registrados em 2008 e 2011. Esta diferença se deve ao fato que a erosividade não depende somente do total precipitado, mas principalmente da intensidade da chuva.

Também é importante observar que existe uma variação grande na erosividade da chuva, e assim a utilização de um valor médio anual como muitos modelos adotam na predição das perdas de solos, pode não ser a forma mais correta para representar bem a perda de solos em um período longo.

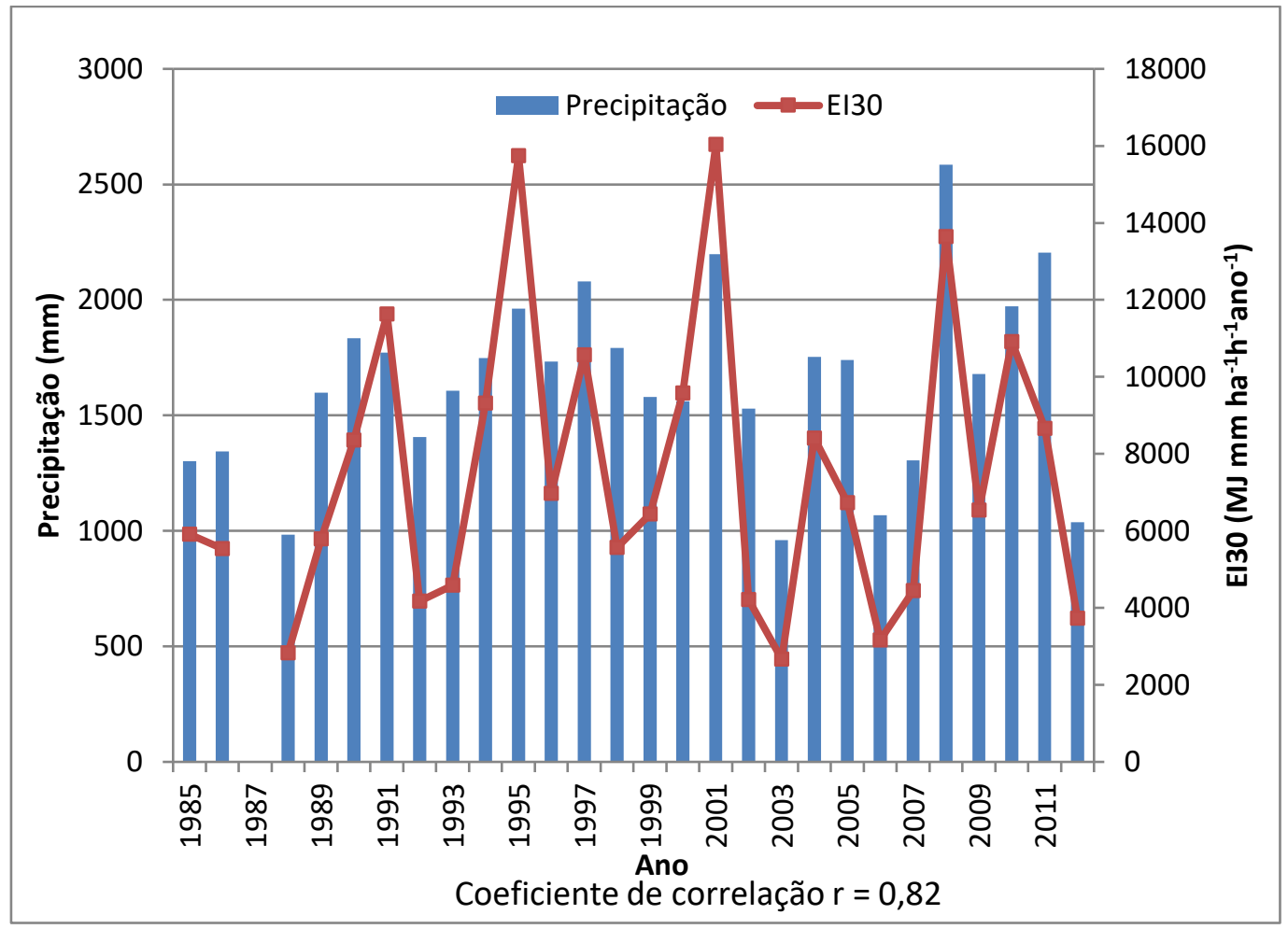

Figura 2 - Totais anuais de erosividade (MJ mm.ha-1. $\left.\mathrm{h}^{-1} \cdot \mathrm{ano}^{-1}\right)$ e precipitação $(\mathrm{mm})$ registrada no pluviógrafo de Florianópolis (SC).

Na figura 3 estão representadas as distribuições relativas do índice de erosividade e da precipitação na escala mensal durante o período analisado. Nessa representação quanto maior a inclinação da curva para determinado período, maior é o risco de ocorrência de erosão no solo, demandando maior atenção com aplicação de práticas conservacionistas neste período. Segundo Dias e Silva (2003), a determinação dos valores de erosividade ao longo do ano permite identificar os meses nos quais os riscos de perda de solo são mais elevados, e por essa razão exerce papel relevante no planejamento de práticas conservacionistas fundamentadas na máxima cobertura do solo nas épocas críticas de maior capacidade erosiva das chuvas.

Para a região de Florianópolis se observa que existe uma variação sazonal mais acentuada, com maior erosividade no verão $(49,5 \%)$ e menor no inverno $(4,4 \%)$ do que constatado para Urussanga (VALVASSORI; BACK, 2014) e Chapecó (Back et al., 2016). Em algumas regiões brasileiras existe 
uma variação sazonal mais acentuada, como observada por Almeida et al. (2012), que destacam uma proporção igual ou maior de $94 \%$ da erosividade ocorrendo nas estações de primavera e verão. Essas diferenças estão relacionadas aos mecanismos formadores da chuva e suas características, sendo que em Florianópolis, no verão predominam as chuvas mais intensas originadas de processos convectivos.

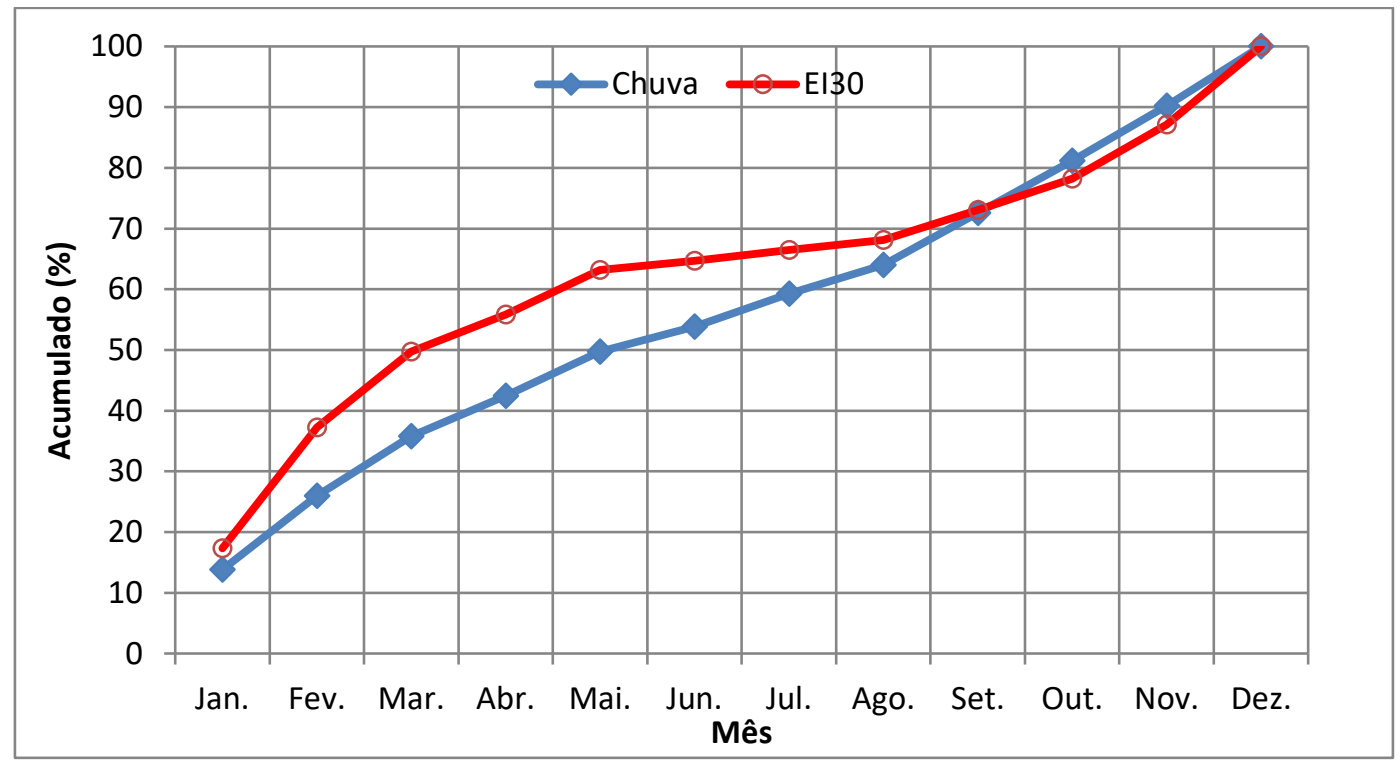

Figura 3 - Distribuição acumulada (\%) da chuva e do Índice de erosividade (EI30) em Florianópolis, SC.

Na figura 4 constam as equações de regressão ajustadas entre o índice de erosividade médio mensal e o coeficiente de chuva de Florianópolis. Observa-se que 0 ajuste para 0 modelo potencial $\left(R^{2}=0,8927\right)$ foi ligeiramente superior que para o modelo linear $\left(R^{2}=0,8427\right)$, e ambos modelos foram estatisticamente significativos $(p<0,05)$ e assim podem ser usados na estimativa da erosividade pelo método pluviométrico.

Destaca-se que alguns autores encontraram valores mais elevados do coeficiente de determinação, como Cassol et al. (2008), que obtiveram $\mathrm{R}^{2}$ de 0,96 para São Borja (RS), e Almeida et al. (2012) que obtiveram $\mathrm{R}^{2}$ de 0,91 para Cuiabá (MT). No entanto existem também vários trabalhos com $R^{2}$ inferiores como Cassol et al. (2007) que encontraram $\mathrm{R}^{2}$ de apenas 0,53 para o município de Ijuí (RS). Gonçalves et al. (2006) trabalhando com catorze estações pluviográficas do estado do Rio de Janeiro encontraram valores do coeficiente $\mathrm{R}^{2}$ variando de 0,40 a 0,98. Oliveira Júnior e Fernandez Medina (1990), avaliando a erosividade de Manaus (AM), obtiveram $R^{2}$ de 0,52 e ressaltam que embora as correlações não foram elevadas, foram significativas pelo teste t ao nível de significância de $1 \%$.

Silva et al. (1997) afirmam que as correlações significativas indicam que o coeficiente de chuva pode ser usado para estimar a erosividade da chuva na ausência de dados pluviográficos. No entanto, ressaltam que o uso destas equações está limitado às regiões que apresentam a magnitude dos parâmetros semelhantes aos dos empregados no ajuste das equações. Valvassori e Back (2014) encontraram $\mathrm{R}^{2}=0,908$ para o município de 
Urussanga (SC) e Back et al. (2016) obtiveram $\mathrm{R}^{2}=0,744$ para o município de Chapecó (SC), sendo que em ambos trabalhos o modelo linear foi superior ao modelo potencial. Bertol (1993) e Bertol (1994) analisado dados de Lages (SC) e Campos Novos (SC) também observaram que o modelo linear foi mais adequado, enquanto que Lombardi Neto (1977) analisando dados de Campinas (SP), Carvalho (1987) analisando dados de Mococa (SP) e Sosa (1987) analisando dados de Pindorama (SP) constataram que o modelo potencial foi mais adequado.

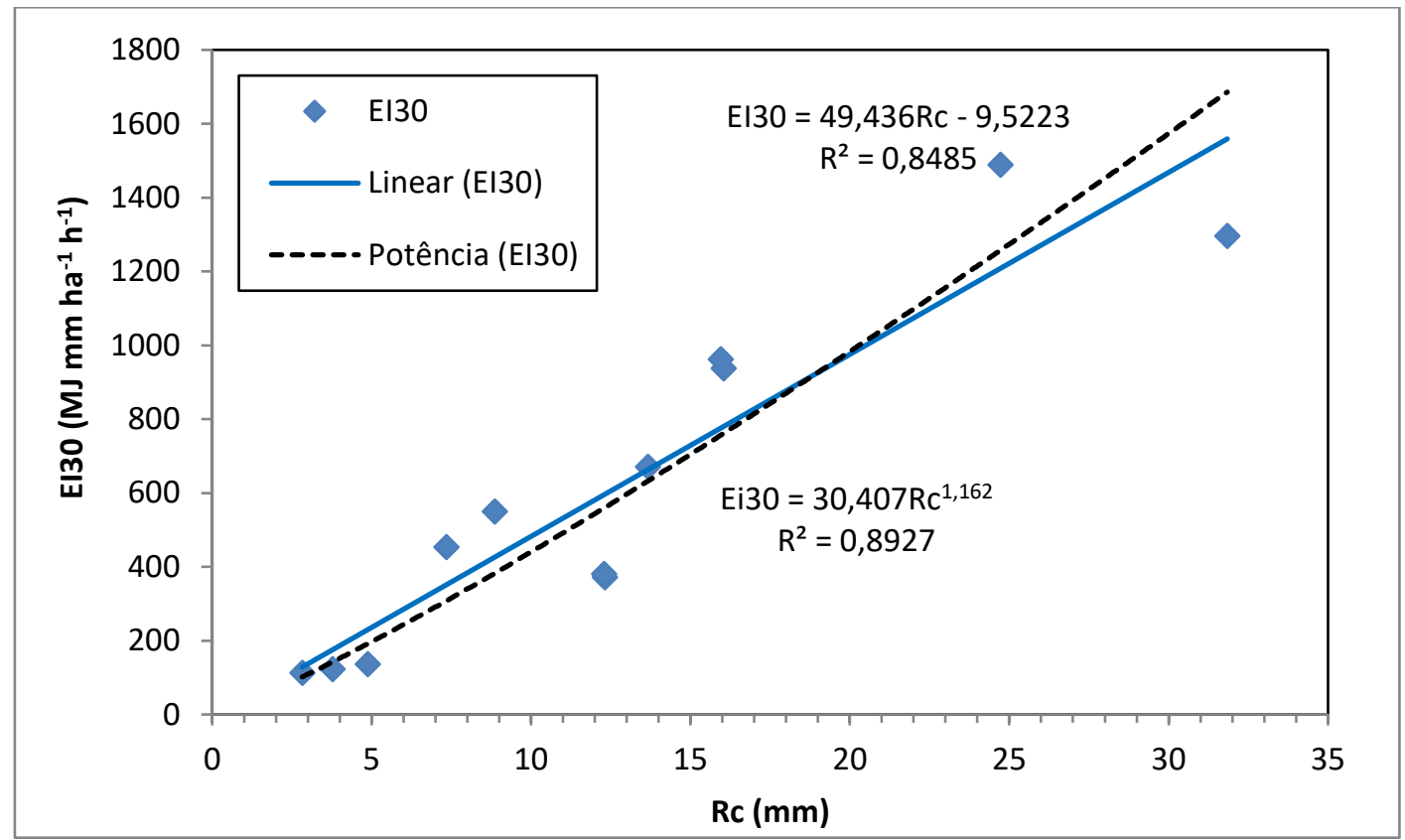

Figura 4 - Curvas de ajuste entre o índice de erosividade EI30 médio mensal e o coeficiente de chuva (RC) para Florianópolis, SC.

Na figura 5 está representada distribuição de probabilidade GumbelChow ajustada à série de máximas anuais de intensidade máximas em 30 minutos (I30). O valor da estatística calculada do teste KS (Dmax=0,093) foi inferior ao valor crítico para o nível de significância de 5\% (Dcrit $=0,254$ ), indicando que a distribuição pode ser utilizada na estimativa dos valores de I30.

$\mathrm{Na}$ figura 6 está representada a distribuição de probabilidade de Gumbel-Chow ajustada aos valores de erosividade anual (EI30). O valor da estatística Kolmogorov-Smirnov (Dmax $=0,0681$ ) também foi inferior ao valor crítico do teste de Kolmogorov-Smirnov, mostrando que esta distribuição pode ser usada na estimativa dos valores de erosividade anual.

Os valores estimados contam na tabela 4, na qual observa-se que a intensidade da chuva com duração de 30 minutos período de retorno de 2 anos é de $63,8 \mathrm{~mm} . \mathrm{h}^{-1}$. Para o período de retorno de 5 anos obtém-se o valor de $78,3 \mathrm{~mm} \cdot \mathrm{h}^{-1}$. A intensidade da chuva com duração de 30 minutos é uma informação utilizada no modelo hidrológico Soil and Water Assessment Tool (SWAT) como parâmetro do gerador climático para estimar as chuvas máximas. 
A erosividade anual com período de retorno de 5 anos foi estimada com 10.759,1 MJ mm.ha-1. $\mathrm{h}^{-1}$.ano-1, para período de retorno de 10 anos o valor passa para 13.299,9 MJ mm.ha-1. $\mathrm{h}^{-1}$.ano ${ }^{-1}$, valor próximo do dobro da erosividade média anual. Esta informação é importante e pode-se avaliar a possibilidade de incluir um fator de risco como o período de retorno nos modelos de previsão de perdas de solos, utilizando valores diferentes do valor médio. Sadeghi et al. (2017) comentam que a análise do período de retorno é uma ferramenta para ajudar os engenheiros a lidar com a incerteza, e é importante para se tomar as melhores decisões para controlar e controlar a erosão do solo com base em análises de informações e eventos aceitáveis que ocorram no passado.

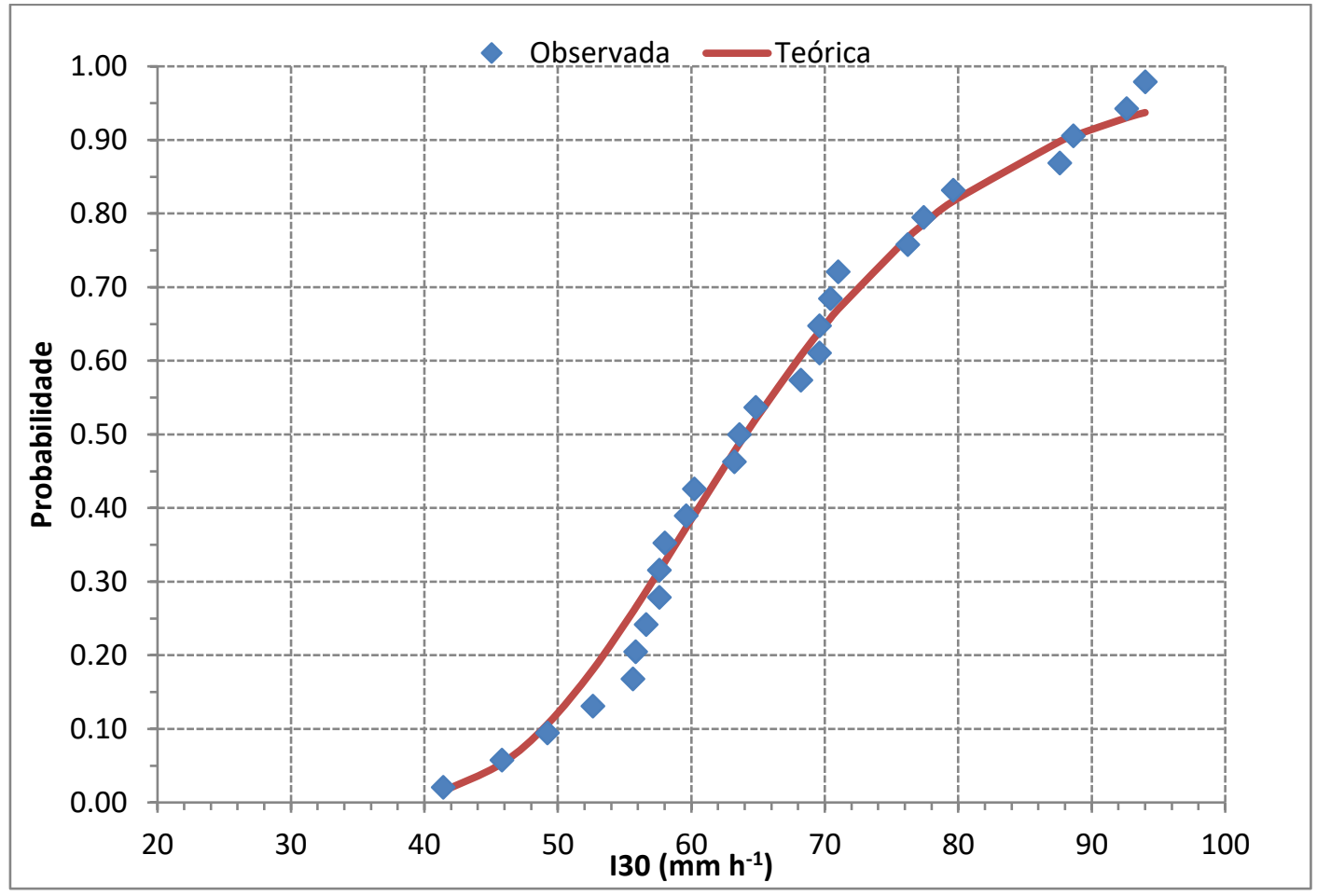

Figura 5: Aderência das distribuições ajustada à série de máximas anuais de intensidade de chuva em 30 minutos (I30) de Florianópolis, SC. 


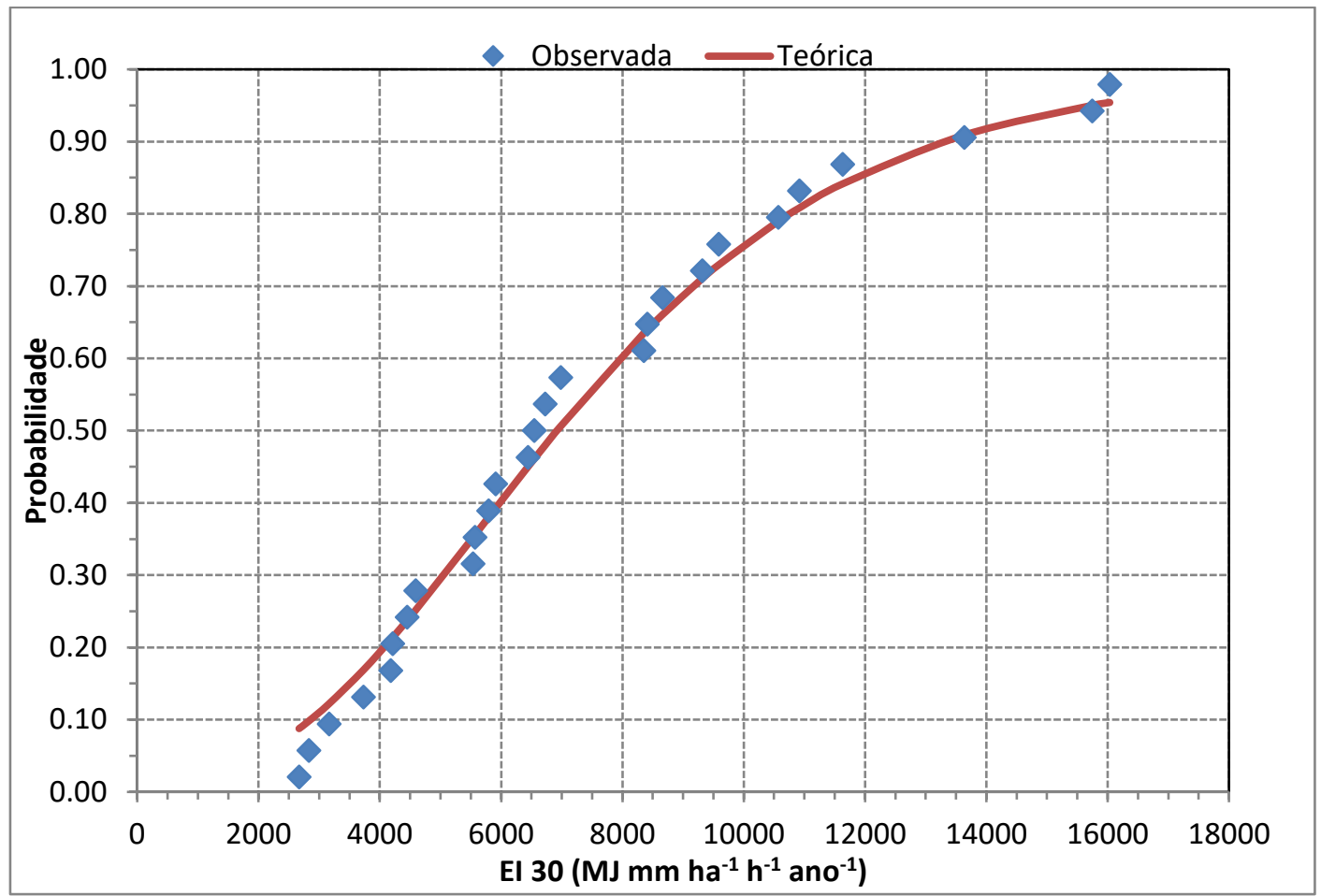

Figura 6: Aderência da distribuição ajustada à série de chuvas erosivas anuais (EI30) de Florianópolis, SC.

Tabela 4: Valores estimados de intensidade máxima da chuva em 30 minutos (I30) e da chuva erosiva anual (EI30) para Florianópolis, SC.

\begin{tabular}{cccc}
\hline $\begin{array}{c}\text { T - Período de retorno } \\
\text { (anos) }\end{array}$ & $\begin{array}{c}\text { Probabilidade } \\
\mathrm{P}[\leq \mathrm{X}]\end{array}$ & $\begin{array}{c}\mathrm{I}_{30} \\
\left(\mathrm{~mm} \cdot \mathrm{h}^{-1}\right)\end{array}$ & $\begin{array}{c}\mathrm{EI}_{30} \\
\left(\mathrm{MJ} \mathrm{mm} \cdot \mathrm{ha}^{-1} \cdot \mathrm{h}^{-1} \cdot \mathrm{ano}^{-1}\right)\end{array}$ \\
\hline 2 & 0,50 & 63,8 & $6.921,6$ \\
5 & 0,80 & 78,3 & $10.759,1$ \\
10 & 0,90 & 88,0 & $13.299,9$ \\
20 & 0,95 & 97,2 & $15.737,0$ \\
25 & 0,96 & 100,2 & $16.510,1$ \\
50 & 0,98 & 109,2 & $18.891,7$ \\
100 & 0,99 & 118,2 & $21.255,6$ \\
\hline
\end{tabular}

\section{CONCLUSÕES}

Com base nos resultados obtidos pode-se concluir que:

1) As chuvas erosivas em Florianópolis representam $80,2 \%$ da chuva total anual;

2) Existe uma variação sazonal na erosividade, com maiores valores de erosividade no verão $(49,5 \%)$ e menores no inverno $(8,4 \%)$;

3) Nos meses de janeiro e fevereiro a erosividade são classificadas como muito altas, em março e dezembro como altas, e nos meses de junho a agosto com erosividade muito baixas; 
4) A erosividade média anual é de $7.522 \mathrm{MJ} \mathrm{mm} \cdot \mathrm{ha}^{-1} \cdot \mathrm{h}^{-1} \cdot \mathrm{ano}^{-1}$, classificada com erosividade alta;

5) Embora das equações de regressão ajustadas entre o índice de erosividade com coeficiente de chuva e ou a chuva mensal, o melhor modelo foi o potencial, todas equações podem ser usadas na estimativa da erosividade em locais da região de Florianópolis onde somente se dispõem de dados pluviométricos;

6) As séries de máximas anuais de intensidade da chuva com duração e a erosividade anual se ajustaram satisfatoriamente à distribuição de Gumbel-Chow

7) A utilização dos valores de erosividade da chuva para determinado período de retorno permite aplicar um fator de risco nos modelos de perdas de solos.

\section{AGRADECIMENTOS}

Os autores agradecem ao Conselho Nacional de Desenvolvimento Cientifico e Tecnológico ( $\mathrm{CNPq}$ ) pelo apoio financeiro a esta pesquisa.

\section{REFERÊNCIAS BIBLIOGRÁFICAS}

ALMEIDA, C. O. S.; AMORIM, R. S. S.; ELTZ, F. L. F.; COUTO, E. G.; JORDANI, S. A. Erosividade da chuva em municípios do Mato Grosso: Distribuição sazonal e correlações com dados pluviométricos. Revista Brasileira de Engenharia Agrícola e Ambiental, Campina Grande, v. 16, n. 2, p. 142-152, 2012.

ALVARES, C. A.; STAPE, J. L.; SENTELhAS, P. C.; GONÇALVES, J. L. M.; SPAROVEK, G. Köppen's climate classification map for Brazil. Meteorologische Zeitschrift, Stuttgart, v. 22, n. 6, p. 711-728, 2014.

AMORIM, R. S. S.; SILVA, D. D. da; PRUSKI, F. F.; MATOS, A. T. Avaliação do desempenho dos modelos de predição da erosão hídrica USLE, RUSLE e WEPP para diferentes condições edafoclimáticas do Brasil. Engenharia Agrícola, Jaboticabal, v. 30, n. 6, p. 1046-1049, 2010.

BACK, A. J.; ALBERTON, J. V.; POLETO, C. Avaliação da erosividade das chuvas de Chapecó, Santa Catarina. In: Simpósio sobre Sistemas Sustentáveis, 3. Porto Alegre, 2016. p.1-6.

BERTOL, I. Avaliação da erosividade da chuva na localidade de Campos Novos (SC) no período de 1981-1990. Pesquisa Agropecuária Brasileira, Brasília, v. 29, p. 1453-1458, 1994.

BERTOL, I. Índice de erosividade (EI30) para Lages (SC) - 1a aproximação. Pesquisa Agropecuária Brasileira, Brasília, v.28, n.4, p.515-21, abr. 1993.

BERTONI, J.; LOMBARDI NETO, F. Conservação do solo. 2.ed. São Paulo, Ícone, 1990. 355p.

BESKOW, S.; MELLO, C.R.; NORTON, D.L.; CURI, N.; VIOLA, M.R.; AVANZI, J. C. Soil erosion prediction in the Grande River Basin, Brazil using distributed model. Catena, v. 79, p. 49-59, 2009. 
BORRELLI, P.; DIODATO, N.; PANAGOS, P. Rainfall erosivity in Italy: a national scale spatio-temporal assessment. International Journal of Digital Earth, v.9, n.9, p.835-850, 2016.

CABEDA, M. S. V. Computation of storm EI values. West Lafayette, Purdue University, 1976. 6p.

CASSOL, E. A.; MARTINS, D.; ELTZ, F. L. F.; LIMA, V. S. ; BUENO, A. C. Erosividade e padrões hidrológicos das chuvas de Ijuí (RS) no período de 1963 a 1993. Revista Brasileira de Agrometeorologia, Santa Maria, v. 15, p. 220231, 2007.

CASSOL, E. A.; ELTZ, F. L. F.; MARTINS, D.; LEMOS, A. M.; LIMA, V. D.; BUENO, A. C. Erosividade, padrões hidrológicos, período de retorno e probabilidade de ocorrência das chuvas em São Borja, RS. Revista Brasileira de Ciência do Solo, Viçosa, v. 32, p.1239-1251, 2008.

CARVALHO, M. P. Erosividade da chuva: distribuição e correlação com as perdas de solo de Mococa - SP. Piracicaba, SP: USP, 1987. 104 f. Dissertação (Mestrado em Solos e Nutrição de Plantas) - Escola Superior de Agricultura "Luiz de Queiroz", Universidade de São Paulo, Piracicaba

CARVALHO, N. O. Hidrossedimentologia prática. 2.ed. Rio de Janeiro, Interciência, 2012. 599p.

COGO, N. P.; DREWS, C. R.; GIANELLO, C. Índice de erosividade das chuvas dos municípios de Guaíba, Ijuí e Passo Fundo, no Estado do Rio Grande do Sul. In: ENCONTRO NACIONAL DE PESQUISA SOBRE CONSERVAÇÃO DO SOLO, 2., 1978, Passo Fundo. Anais... Passo Fundo, RS: CNTRIGO; EMBRAPA; SNLCS, 1978. p.145-52.

DIAS, A. S.; SILVA, J. R. C. A erosividade das chuvas em Fortaleza (CE). I Distribuição, probabilidade de ocorrência e período de retorno - 1 a. Aproximação. Revista Brasileira de Ciência do Solo, Viçosa, v. 27, p. 335-345, 2013.

FOSTER, G. R.; McCOOL, D. K.; RENARD, K. G.; MOLDENHAUER, W. C. Conversion of the universal soil loss equation to SI units. Journal of Soil and Water Conservation, Baltimore, v. 36, p. 355-9, 1981.

FOURNIER, F. The effect of climatic factors on soil erosion estimates of solids transported in suspension in runoff. [S.I.]: Association Hydrologic Int. Public, 1956. v.38, 6 p.

FRANCO, A. C.; CZARNOBAI, A. F.; PRUDÊNCIO, R. S. Estudo do regime de ventos para Florianópolis/SC. In: VII Simpósio Brasileiro de Climatologia Geográfica, Rondonópolis, MT. Anais, MT. Anais. 2006.

GONÇALVES, F. A.; SILVA, D. D. da; PRUSKI, F. F.; CARVALHO, D. F. da; CRUZ, E. S. da. Índices e espacialização da erosividade das chuvas para o Estado do Rio de Janeiro. Revista Brasileira de Engenharia Agrícola e Ambiental, Campina Grande, v. 10, n. 2, p. 269-276, 2006.

GRIMM, A. M.; FERRAZ, S. E. T.; GOMES, J. Precipitation Anomalies in Southern Brazil Associated with El Niño and La Niña Events. Journal of Climate, v. 11, n. 11, p. 2863-2880, 1998. 
HERNANDO, D., AND ROMANA, M. G. (2016). Estimate of the (R)USLE rainfall erosivity factor from monthly precipitation data in mainland Spain. Journal of Iberian Geology, v. 42, n. 1, p. 113-124, 2016.

KINNELL, P. I. A. Event soil loss, runoff and the universal soil loss equation family of models: a review. Journal of Hydrology, v.385, p. 384-397, 2010.

KITE, G.W. Frequency and risk analyses in hydrology. Fort Collins, Water Resources Publications, 1977. 224p.

LEE, M. H.; LIN, H. H. Evaluation of annual rainfall erosivity index based on daily, Monthly, and annual precipitation data of rainfall station network in southern Taiwan. International Journal of Distributed Sensor Networks, 2015, $15 p$.

LOBO, G. P.; BONILLA, C. A. Effect of temporal resolution on rainfall erosivity estimates in zones of precipitation caused by frontal systems. Catena, v. 135, p. 202-207, 2015.

LOMBARDI NETO, F. Rainfall erosivity - its distribution and relationship with soil loss at Campinas, Brazil. West Lafayette, Purdue University. 1977. 53p.

MAIA, A. G.; VILLELA, S. M. A necessidade da consideração do processo de assoreamento no planejamento e operação de reservatórios. Revista Brasileira de Recursos Hídricos, v. 11, n.2, p. 187-193, 2006.

MARTINS, S. G.; AVANZI, J. C.; SILVA, M. L. N.; CURI, N.; NORTON, L. D.; FONSECA, S. Rainfall erosivity and rainfall return period in the experimental watershed of Aracruz, in coastal plain of Espírito Santo, Brazil. Revista Brasileira de Ciência do Solo, Viçosa, V. 34, p. 999-1004, 2010.

MAZURANA, J.; CASSOL, E. A.; SANTOS, L. C.; ELTZ, F. L. F.; BUENO, A. C. Erosividade, padrões hidrológicos e período de retorno das chuvas erosivas de Santa Rosa (RS). Revista Brasileira de Engenharia Agrícola e Ambiental, v.13, p.975-983, 2009.

MEDINA, B. F.; OLIVEIRA JÚNIOR, R. C. A aplicabilidade de alguns índices erosivos em Latossolo Amarelo de Manaus (AM). Revista Brasileira de Ciência do Solo, Campinas, v.11, n.1, p.67-70, 1987.

MELLO, C. R.; VIOLA, M. R.; BESKOW, S.; NORTON, L. D. Multivariate models for annual rainfall erosivity in Brazil. Geoderma, v. 202 -203, p. 88-102. 2013.

MELLO, C. R.; SÁ, M. A. C.; CURI, N.; MELLO, J. M.; VIOLA, M. R. Erosividade mensal e anual da chuva no Estado de Minas Gerais. Pesquisa Agropecuária Brasileira, Brasília, v.42, p, 537-545, 2007.

MORRIS, G. L.; FAN, J. Reservoir sedimentation handbook: design and management of dams, reservoirs, and watersheds for sustainable Use. Eletronic ver. 1.04. McGraw-Hill. New York, 2010.

NAIPAL, V.; REICK, C.; PONGRATZ, J.; VAN OOST, K. Improving the global applicability of the RUSLE model - adjustment of the topographical and rainfall erosivity factors. Geoscientific Model Development, v.8, p. 2893-2913, 2015.

OLIVEIRA, P. T. S.; WENDLAND, E.; NEARING, M. A. Rainfall erosivity in Brazil: A review, Catena, v. 100, p. 139-147, 2012. 
OLIVEIRA JÚNIRO, R. C.; FERNANDEZ MEDINA, B. A erosividade das chuvas em Manaus (AM). Revista brasileira de ciência do solo, Campinas, v. 14, p. 235-239, 1990.

PANAGOS, P.; BALLABIO, C.; BORRELLI, P.; MEUSBURGER, K.; KLIKC, A.; ROUSSEVA, S.; PER `CEC TADI'C M.; MICHAELIDES, S.; HRABALÍKOVÁ,M.; OLSEN, P.; AALTO, J.; LAKATOS, M.; RYMSZEWICZ, A.; DUMITRESCU,A.; BEGUERÍA, S.; ALEWELL C. Rainfall erosivity in Europe, Science of the Total Environment, v. 511, p. 801-814, 2015.

PEÑALVA BAZZANO, M. G.; ELTZ, F. L. F.; CASSOL, E. A. Erosividade e características hidrológicas das chuvas de Rio Grande (RS). Revista Brasileira de Ciência do Solo, Viçosa, v. 34, p. 235-244, 2010.

PEÑALVA BAZZANO, M. G.; ELTZ, F. L. F.; CASSOL, E. A. Erosividade, coeficiente de chuva, padrões e período de retorno das chuvas de Quaraí, RS. Revista Brasileira Ciência do Solo, Viçosa, v. 31, p. 1205-1217, 2007.

PRUDÊNCIO, R. S. Estudo do sistema de circulação de brisa no litoral centronorte de Santa Catarina. Dissertação, Faculdade de Meteorologia, Universidade Federal de Pelotas, Pelotas, 2002. 456p.

PRUSKI, F. F. Conservação do solo e água: práticas mecânicas para o controle da erosão hídrica. 2. ed. Viçosa: UFV, 2009. 279p.

RENARD, K. G.; FOSTE, G. R.; WEESIES, G. A.; McCOOL, D. K; YODER, D. C. Predicting soil erosion by water: a guide to conservation planning with the Revised Universal Soil Loss Equation (RUSLE). U.S. Department of Agriculture, Agriculture Handbook No. 703, 404 pp. 1997.

SADEGHI, S. H.; ZABIHI, M.; VAFAKHAH, M.; HAZBAVI, Z. Spatiotemporal mapping of rainfall erosivity index for different return periods in Iran. Natural Hazards, v. 87, p. 35-56, 2017.

SADEGHI, S. H. R.; TAVANGAR, S. Development of stational models for estimation of rainfall erosivity factor in different timescales, Natural Hazards, v. 77, p. $429-443,2015$.

SADEGHI, S. H. R.; MOATAMEDNIA, M.; BEHZADFAR, M. Spatial and temporal variations in the rainfall erosivity factor in Iran, Journal of Agricultural Science and Technology, v. 13, p. 451-464, 2011.

SANTOS, C. N. El Niño, La Niña e a erosividade das chuvas no Estado do Rio Grande do Sul. Universidade Federal de Pelotas, Faculdade de Agronomia Eliseu Maciel, Programa de Pós-Graduação em Agronomia. 2008.

SCHICK, J.; BERTOL, I.; COGO, N. P.; GONZÁLEZ, A. P. Erosividade de chuvas em Lages, Santa Catarina. Revista Brasileira de Ciência do solo, v. 38, p. 1890-1905, 2014.

SILVA, M. L. N.; FREITAS, P. L.; BLANCANEAUX, P.; CURI, N. Índices de erosividade das chuvas da região de Goiânia, GO. Revista Brasileira de Ciência do Solo, Viçosa, v. 32, n. 10, p. 275-89, 1997.

SOSA, D. A. Erosividade da chuva. Distribuição e correlação com as perdas de solo para Pindorama, São Paulo, Brasil. Piracicaba, SP: ESALQ, 1987. 105 f. Dissertação (Mestrado em Agronomia) - Escola Superior de Agricultura "Luiz de Queiroz", Piracicaba. 
SYVITSKI, J.P.M.; KETTNER, A. Sediment flux and the Anthropocene. Philosophical Transactions of de Royal Society, v.369, p.957-975, 2011.

THOME, V. M. R.; ZAMPIERI, S. BRAGA, H. J.; PANDOLFO, C.; SILVA JUNIOR, V. P. da; BACIC, I.; LAUS NETO, J.; SOLDATELI, D.; GEBLER, E.; ORE, J. D.; ECHEVERRIA, L.; MATTOS, M.; SUSKI, P. P. Zoneamento Agroecológico e Socioeconômico de Santa Catarina. Florianópolis, 1999. CD-ROOM.

VALVASSORI, M. L; BACK, Á. J. Avaliação do potencial erosivo das chuvas em Urussanga, SC, no período de 1980 a 2012. Revista Brasileira de Ciência do Solo, Viçosa, v. 38, p. 1011-1019, 2014.

WANG, B.; ZHENG, F. GUAN, Y. Improved USLE-K factor prediction: A case study on water erosion areas in China. International Soil and Water Conservation Research, v. 4, p. 168-176, 2016.

WISCHMEIER, W. H.; SMITH, D. D. Rainfall energy and its relationship to soil loss. Transactions of the American Geophysical Union, v. 39, p. 285-91, 1958.

WISCHMEIER, W. H.; SMITH, D. D. Predicting rainfall erosion losses: a guide to conservation planning. U.S Department of Agriculture, Agr. Handbook, 537:1-58, 1978.

YIN, S.; XIE, B.; LIU, B.; NEARING, M. A. Rainfall erosivity estimation based on rainfall data collected over range of temporal resolutions. Hydrology and Earth System Sciences, v. 19, p. 4113-4126, 2015.

ZHANG, W. B.; FU, J. S. Rainfall erosivity estimation under different rainfall amount, Resources Science, v. 25, p. 35-41, 2003. 